\title{
Informação arquivística e informação orgânica frente à teoria do conceito
}

\author{
Camila Schwinden Lehmkuhl \\ Universidade Federal de Santa Catarina, Centro de Ciências da Educação, Departamento de Ciência da \\ Informação, Florianópolis, SC, Brasil \\ camila_lehmkuhl@hotmail.com \\ William Barbosa Vianna \\ Universidade Federal de Santa Catarina, Centro de Ciências da Educação, Departamento de Ciência da \\ Informação, Florianópolis, SC, Brasil \\ William.vianna@ufsc.br \\ Eva Cristina Leite da Silva \\ Universidade Federal de Santa Catarina, Centro de Ciências da Educação, Departamento de Ciência da \\ Informação, Florianópolis, SC, Brasil \\ eva.cristina@ufsc.br
}

DOI: https://doi.org/10.26512/rici.v12.n3.2019.25822

Recebido/Recibido/Received: 2018-03-13

Aceitado/Aceptado/Accepted: 2018-08-14

Resumo: O propósito deste artigo é apresentar o que está sendo definido como informação orgânica e informação arquivística no Brasil, levando em conta a teoria do conceito. Justifica-se pelo de que a Arquivologia assiste nos últimos anos novas definições sendo utilizadas para determinar e delimitar seu objeto de estudo e novos conceitos passam a ser utilizados, dentre eles, os de informação arquivística e informação orgânica. Foi realizada a pesquisa bibliográfica na base de periódicos que mais se relaciona à área de Arquivologia no Brasil para identificar autores que têm trabalhando as temáticas citadas; o que está sendo definido sobre o assunto no Brasil; e por fim, apontar possíveis motivos e hipóteses para o uso dos termos na Arquivologia. Como resultados foi possível identificar que há divergências entre as definições, e a partir disso foi possível criar três hipóteses para justificar o uso de ambos os termos.

Palavras-Chave: Arquivologia. Informação Arquivística. Informação orgânica. Teoria do conceito.

\section{Archival information and organic information in the face of concept theory}

Abstract: The objective of this article is to present what is being defined as organic information and archival information in Brazil, considering the concept theory. It is justified by the fact that in recent years, the Department of Archives has seen new definitions being used to determine and delimit its object of study, and new concepts are being used, among them archival information and organic information. The bibliographical research was carried out in the journal base that is most related to the area of Archival Science in Brazil to identify authors who have been working on the topics mentioned; what is being defined on the subject in Brazil; and finally, to point out possible motives and hypotheses for the use of terms in Archival Science. As results it was possible to identify that there are divergences between the definitions, and from this it was possible to create three hypotheses to justify the use of both terms.

Keywords: Archival Information. Archival Science. Concept Theory. Organic Information.

\section{Información archivista e información orgánica frente a la teoría del concepto}

Resumen: El objetivo de este artículo es presentar lo que está siendo definido como información orgánica e información archivística en Brasil, teniendo en cuenta la teoría del concepto. Se justifica por el que la 
Archivología asiste en los últimos años nuevas definiciones siendo utilizadas para determinar y delimitar su objeto de estudio y nuevos conceptos pasan a ser utilizados, entre ellos, los de información archivística e información orgánica. Se realizó la investigación bibliográfica en la base de periódicos que más se relaciona al área de Archivología en Brasil para identificar autores que tienen trabajando las temáticas citadas; lo que está siendo definido sobre el tema en Brasil; y por último, apuntar posibles motivos e hipótesis para el uso de los términos en la Archivología. Como resultados fue posible identificar que hay divergencias entre las definiciones, ya partir de eso fue posible crear tres hipótesis para justificar el uso de ambos términos.

Palabras clave: Archivística. Archivología. Información archivística. Información orgánica. Teoría del concepto.

\section{Introdução}

A Arquivologia vem passando ao longo dos anos por repaginações, alavancadas principalmente pelas alterações assistidas desde a produção até as formas de acesso e armazenamento dos arquivos. A tecnologia tem apresentado novos desafios à área, mas não somente ela, aprofundamentos teóricos e estudos interdisciplinares vêm apresentando rupturas epistemológicas em seu escopo de pesquisa. Sua interdisciplinaridade e alocação no paradigma científico têm instigado teóricos a relacionarem a área com a ciência da informação (Cl),a exemplo, Barros e Martins (2015) no artigo intitulado: “A informação orgânica enquanto um objeto interdisciplinar: as relações entre a arquivística e a ciência da informação no âmbito da representação em arquivos". Nesse sentido, a informação se torna o elemento de intersecção entre as duas áreas. Para tanto, na Arquivologia a informação tem sido utilizada de duas formas distintas: informação orgânica e informação arquivística.

A informação orgânica é trabalhada a partir das perspectivas dos canadenses: Rousseau, Couture e Ducharme, pioneiros no assunto. Já informação arquivística é abordada diferentes autores a partir da década de 1980. Nessa perspectiva, baseando-se na teoria do conceito, como objetivo geral busca-se apresentar o que está sendo definido, ou seja, quais os limites conceituais entre informação orgânica e informação arquivística no Brasil ${ }^{1}$. Enquanto os objetivos específicos estão pautados em: apresentar autores que têm trabalhando as temáticas de informação orgânica e informação arquivística; identificar o que está sendo definido como informação orgânica e informação arquivística no Brasil; e por fim, apontar possíveis motivos e hipóteses para o uso dos termos na Arquivologia.

A natureza da pesquisa é exploratória partindo de um processo de sondagem, com vistas a aprimorar ideias, descrevê-las para posteriormente, construir hipóteses. Usou-se como metodologia a pesquisa bibliográfica na base de dados da área no Brasil, a BRAPCI.

${ }^{1}$ Este artigo é fruto da disciplina cursada no primeiro trimestre letivo de 2017, denominada Epistemologia da Ciência da Informação ofertada pelo Programa de Pós-Graduação em Ciência da Informação da Universidade Federal de Santa Catarina. As referências do ano de 2018 que aparecem no texto foram incluídas após a revisão da revista. 
Quanto aos resultados, foi possível identificar que há realmente diferentes definições sendo dadas para os conceitos de informação orgânica e informação arquivística no Brasil e 3 possíveis hipóteses para essa questão terminológica.

\section{Teoria do conceito}

Para adentrar-se no objetivo principal deste artigo será antes apresentada como aporte teórico a teoria do conceito, para tanto, utilizaremos como referência a autora Dahlberg, uma das percussoras da teoria do conceito.

Ingertraut Dahlberg é adepta a visão positivista em que aplicada à ciência da informação busca conceitos universais que correspondam à verdade e possam ser uma representação acurada da realidade (MELO; BRASCHER, 2014). Ainda segundo Melo e Bräscher (2014, p. 72) "[...] nesta visão, os conceitos são estáticos, verificáveis, exatos e gerais".

Dahlberg (1978, p. 102) define conceito como "a compilação de enunciados verdadeiros sobre determinado objeto, fixada por um símbolo linguístico". Segundo Abbagnano, "para Aristóteles, os conceitos diferem das palavras e das coisas por terem uma realidade mental; conceito é o modo como os homens organizam mentalmente todas as coisas existentes"(ABBAGNANO, 2003, p. 164).

Dalhberg, em seu artigo intitulado "Teoria do conceito" (1978) descreve passo a passo a construção de um conceito. Ela inicia o artigo abordando a linguagem, a qual permite o homem designar os objetos que o circundam. A partir desses vários objetos o homem pode elaborar enunciados sobre os mesmos, será com base em tais enunciados que os conceitos relativos aos diversos objetos serão elaborados. Ela ainda define a formação dos conceitos como a reunião e compilação de enunciados verdadeiros a respeito de determinado objeto (DAHLBERG, 1978).

Quanto às definições, Dalhberg (1978) diz que são pressupostos indispensáveis na argumentação e nas comunicações verbais e que constituem elementos necessários na construção de sistemas científicos. Ela determina a definição como: "definição - df delimitação ou fixação do conteúdo de um conceito (conteúdo do conceito = extensão, ou conjunto de características ou atributos)" (DAHLBERG, 1978, p. 106). De acordo com o que foi demonstrado nestes dois últimos parágrafos, o esquema a seguir busca sistematizar o argumento de Dahlberg. 
Quadro 1 - Compilação de Linguagem, Enunciados,

Conceitos e Definições, baseados em Dahlberg.

- Permite o homem designar os objetos que o circundam.

\section{Linguagem}

- Com os vários objetos que circundam os homens foi possível elaborar enunciados sobre os mesmos.

- É com base em tais enunciados que elaboramos os conceitos relativos aos diversos objetos.

Conceito - Define a formação dos conceitos como a reunião e compilação de enunciados verdadeiros a respeito de determinado objeto.

- A definição é, de certo modo, uma limitação, ou seja, uma colocação de limites. Trata-se de determinar ou fixar os limites de um conceito ou ideia.

Fonte: adaptado de Dahlberg (1978).

Levando em conta o exposto e os objetivos deste artigo, o foco se dará exclusivamente as "definições", ou seja, o que está sendo utilizado como conceito de informação orgânica e informação arquivística para definir ambas. Para tanto, a seguir é contextualizada brevemente a Arquivologia e suas correntes.

\section{Arquivologia}

A Arquivologia como área do saber preza pela preservação e pelo acesso à informação. Durante muito a Arquivologia era vista apenas como uma disciplina prática, em que eram utilizadas técnicas ainda bastante simples para criação de instrumentos de pesquisa, além da adoção de medidas de preservação e conservação.

Com o advento da tecnologia aliado ao ideal da universalidade do acesso à informação para os cidadãos, por exemplo, a Declaração de Direitos Humanos da ONU de 1948, a Arquivologia passa a repensar suas bases teóricas e metodológicas, o arquivo não é mais um espaço de guarda de documentos, para além, é um espaço de construção social. Consequentemente houve uma libertação da área em prol de conhecimento próprio (JENKINSON, 1922 apud ARAÚJO, 2014). 
Segundo Araújo (2013), a necessidade de constituir-se como campo científico, fez com que os conhecimentos arquivísticos se aproximassem do positivismo, seguindo o modelo das ciências da natureza. Esse conhecimento próprio vem gerando diferentes estudos e aprofundamentos ao longo dos anos pelos arquivistas, questões essenciais para a construção de um corpo teórico. Um desses conceitos é o de arquivo enquanto informação arquivística e informação orgânica provindo de correntes arquivísticas.

Para Messias (2005) a informação representa duas fases distintas. Uma relacionada ao que pode dubiamente representar o momento em que o homem delimita o pensamento/ideia (substância imaterial) e molda-o, transmuta-o para uma forma simbólica, capaz de ser apreendida e comunicada. A outra fase indica o "conteúdo" propriamente dito da mensagem, nesse sentido, tem-se que a informação é o resultado do ato de informar (conteúdo) e o próprio ato (forma) (MESSIAS, 2005). Nesse sentido, a ciência que tem por objeto a informação se torna um campo interdisciplinar principalmente preocupado com a análise, coleta, classificação, manipulação, armazenamento, recuperação e disseminação da informação (BRITO, 2017).

A Arquivologia, por sua vez, estuda as funções do arquivo, os princípios e técnicas a serem observados na: produção, organização, guarda, preservação e utilização dos arquivos (BRASIL, 2005). Com as duas definições fica claro que há algumas semelhanças entre a Ciência da Informação e a Arquivologia principalmente quando do objetivo de dar acesso à informação. Para os autores, como já relacionado na introdução, Barros e Martins (2015), o uso do termo informação na Arquivologia, aumenta suas relações com a Ciência da Informação, já que as duas passam a ter como objeto de estudo a informação.

No decorrer da história da Arquivologia, diferentes correntes sugiram, dentre elas: records management; Tradicional; Integrada; Pós-moderna, cada uma com características e influências diversas. Não caberá aqui exemplificar todas, mas trazer a que propiciou o fenômeno da gestão integrada dos documentos arquivísticos no final dos anos 1980 pelos autores canadenses Couture, Ducharme e Rousseau, a Arquivística Integrada. Essa corrente proporcionou a união da norte-americana records management, a qual considera que os documentos correntes e intermediários devem ser isolados dos permanentes, da mesma maneira que os profissionais que lidam com eles (TOGNOLI, 2012), e a corrente tradicional com origem europeia e relacionada aos arquivos definitivos (históricos).

A Arquivística integrada surge nos anos 1980, no Canadá, apresentando uma visão sistêmica do fluxo documental (ARAÚJO, 2013). Ela passa a ter seus estudos voltados para o tratamento da informação orgânica, objeto de estudo desse artigo, ou seja, aquela que é fruto "natural" das ações que circundam o dia a dia de uma organização ou pessoa. Nesse contexto, a Arquivologia deixa de ser uma disciplina com a função única e exclusiva de guardiã de 
documentos e passa a ter maior preocupação com o fenômeno informação: "[...] elemento fundamental para o funcionamento e desenvolvimento de qualquer organização devendo ser gerida de forma eficaz" (TOGNOLI, 2012, p. 118).

Segundo Rousseau e Couture (1998, p. 70) a arquivística integrada possui três objetivos:

- garantir a unidade e a continuidade das intervenções do arquivista nos documentos de um organismo e permitir, assim uma perspectiva do princípio das três idades e das noções de valor primário e secundário; - permitir a articulação e a estruturação das atividades arquivísticas numa política de organização dos arquivos; - unir o valor primário e o valor secundário numa definição alargada de arquivo.

Nesse contexto, se considera que a arquivística integrada está claramente preocupada com a aproximação das idades dos arquivos; com o papel do arquivista mais presente na organização e planejamento do arquivo e suas atividades, deixando de ser um guardião de documentos antigos; além de que ao considerar essa "definição alargada de arquivo" está se tratando do fenômeno informação, deixando de ter como objeto de estudo documentos estáticos, passando a ter objetos dinâmicos, vivos.

Termos como informação orgânica e informação arquivística passam a ser inseridos nas discussões da Arquivologia. A informação orgânica, como apresentado, a partir da perspectiva da arquivística integrada. E a informação arquivística, segundo Silva (2010, p. 12) “[...] emerge na literatura da área nos anos 1980, estabelecendo a abordagem informacional que inscreve o arquivo na dinâmica da importância que assume a informação na contemporaneidade".

Para Lopes (1996) (apud CALDERON, 2013) até a década de 1990, o conceito de informação arquivística era pouco conhecido na literatura mundial especializada. Esse conceito começa a surgir timidamente, mas no século XXI já é possível notar na literatura da área certa frequência do termo "informação arquivística", o que sinaliza o deslocamento paradigmático do objeto de estudo - do arquivo para a informação arquivística.

\section{Metodologia e coleta de dados}

A metodologia da presente pesquisa possui abordagem qualitativa, de cunho exploratório, em que se buscou traçar hipóteses que expliquem o uso dos termos: informação orgânica e informação arquivística no Brasil.

Foi realizada uma pesquisa bibliográfica na base de periódicos que mais se relaciona à área de Arquivologia no Brasil e que mais abrange produção científica da área, a Base de Dados Referenciais de Artigos de Periódicos em Ciência da Informação (BRAPCI). A pesquisa nessa base foi realizada no mês de julho de 2017 e se restringiu ao campo de busca "informação orgânica" e "informação arquivística”, durante os períodos de 2010 até 2017.

A delimitação do período foi feita por conta de um artigo encontrado na base de dados Scopus intitulado "Información archivística e información orgánica: una análisis conceptual de 
la literatura brasileña" publicado na revista Profisional de La Informacion em 2010 pelas autoras brasileiras Marta Ligia Valentim e Mariana Lousada. Nesse artigo, as autoras, quando tratam da metodologia apresentam uma análise de bibliografia, porém não fica explícito onde foi e como foi realizada a pesquisa.

Levando em conta que se passaram oito anos da publicação do referido artigo, e que dos resultados selecionados para a pesquisa "informação orgânica", por exemplo, que teve11 artigos selecionados, dois são de anos anteriores a 2010 e um de 2010, porém não utilizado pela citada pesquisa, sendo considerado hábil para esta. Dessa forma, busca-se atualizar a referida busca e verificar a eventual evolução no uso dos termos, além de trazer novas abordagens quando dos resultados encontrados.

\subsection{Informação Orgânica}

A princípio foi realizada a busca pelo termo "Informação Orgânica" e foram recuperados 21 resultados, sendo possível identificar, nesse primeiro momento, que as revistas que mais publicam nessa temática são: Informação Arquivística e Ágora, a exemplo como apresentado na figura 1.

Figura 1: Print-Screen página da BRAPCI -resultados para "informação orgânica"

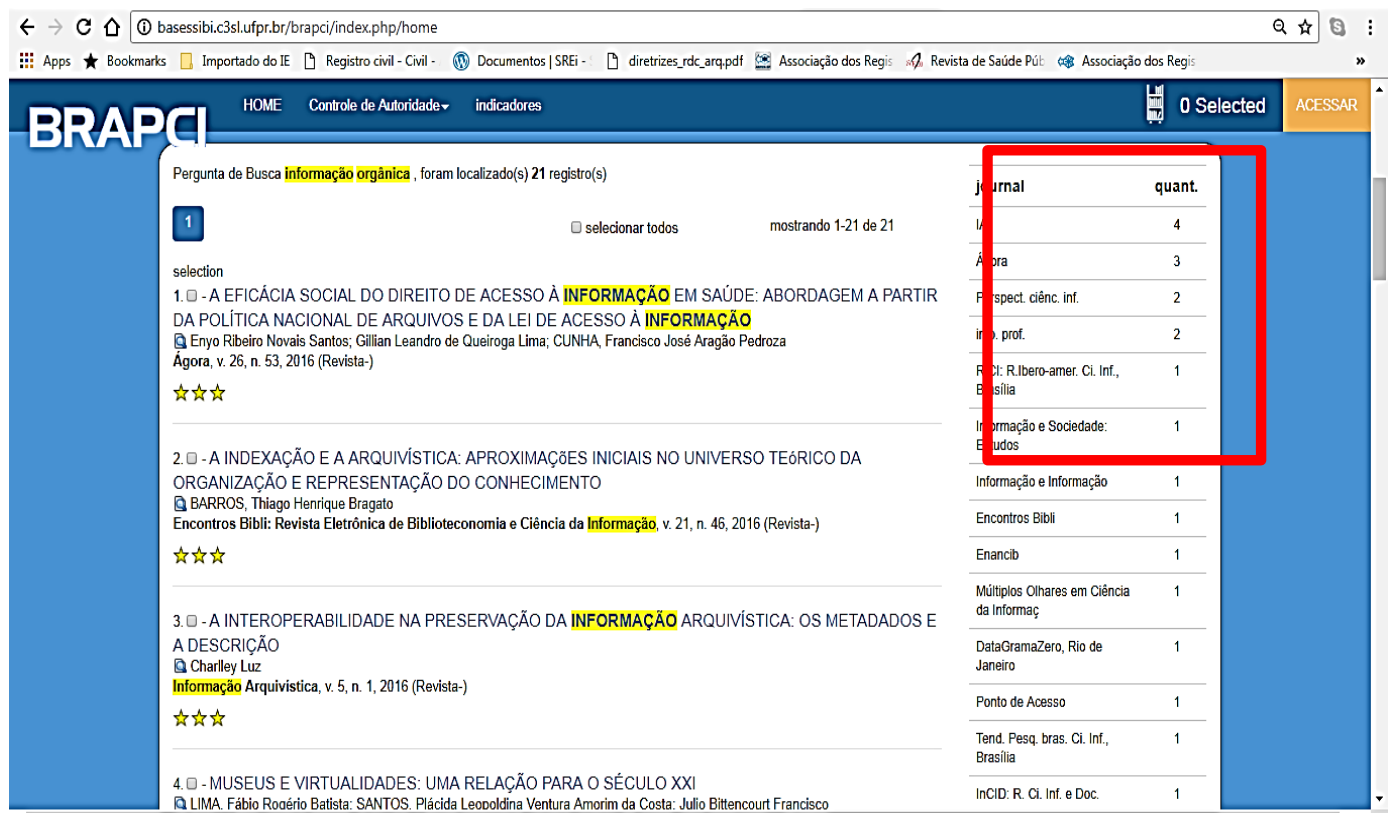

Fonte: dados da pesquisa, 2017

Dos 21 resultados recuperados, um era uma resenha e não foi considerada. Todos os outros 20artigos foram abertos e foi feita a leitura do resumo. Posteriormente foram

\footnotetext{
2 Informação Arquivística e Informação Orgânica: uma análise conceitual na literatura brasileira. Disponível em: <http://www.elprofesionaldelainformacion.com/contenidos/2010/julio/10.pdf>. Acesso em 21 jun. 2018.
} 
pesquisados os termos "informação orgânica" no corpus do texto e feita leitura do contexto. Por fim, nove artigos foram escolhidos. Dentre estes foram selecionados os parágrafos que abordavam definições e contextualizações relacionadas à informação orgânica. Como apresentado no quadro 1. 
4.1.1Quadro 1: Apresentação das definições recuperadas para o termo "informação orgânica".

\begin{tabular}{|c|c|c|}
\hline 1. & & $\begin{array}{l}\text { A Arquivística Integrada traria em seu escopo a análise do que seria a informação orgânica passando a designá-la } \\
\text { como seu objeto, em substituição do termo documento de arquivo. } \\
\text { Informação orgânica estabelece um direito, comprova ou testemunha uma determinada ação jurídica, } \\
\text { administrativa, ou seja, um tipo de informação que é profundamente regulada e controlada por instâncias sociais e } \\
\text { institucionais (BARROS, 2013). } \\
\text { [...] "pode ser ou orgânica, isto é, elaborada, enviada ou recebida no âmbito da sua missão, ou não orgânica, isto é, } \\
\text { produzida fora do âmbito desta" (ROSSEAU; COUTURE, 1998, p. 64). Diante do exposto, a informação orgânica para } \\
\text { arquivística é aquela resultante da sua função finalística, no cumprimento de sua missão institucional. } \\
\text { A abordagem dos pontos de contatos e semelhanças existentes entre Arquivística e Ciência da Informação, } \\
\text { conforme delimitamos, só será possível, de acordo Smith (1999-2000, p. 3), "[...] se analisada de um ponto de vista } \\
\text { diacrônico no qual a ênfase no documento é substituída pela ênfase da informação". }\end{array}$ \\
\hline & $\begin{array}{l}\text { ROCKEMBACH, M. Difusão em arquivos: uma função arquivística, } \\
\text { informacional e comunicacional. Informação Arquivística, v. 4, n. 1, } \\
2015 . \quad \text { Disponível } \\
\begin{array}{l}<\text { http://basessibi.c3sl.ufpr.br/brapci/v/a/18223>. Acesso em: } 30 \text { Nov. } \\
2017 .\end{array}\end{array}$ & $\begin{array}{l}\text { A informação de que tratamos aqui é a orgânica, que adjetiva e delimita a informação que definimos como objeto } \\
\text { de estudo e também está relacionada ao princípio de organicidade, fundamento da Arquivologia. Lopes diz que "é } \\
\text { orgânica a informação que pertence à pessoa ou a organização que a acumulou" (LOPES, 1996, p.32), ou seja, está } \\
\text { vinculada ao caráter natural de produção de informação e documentos a partir das atividades desenvolvidas, seja } \\
\text { individual, coletiva ou organizacional. }\end{array}$ \\
\hline & $\begin{array}{l}\text { LOUSADA, M. Organic production documentary on small business } \\
\text { retail sector of Marília /São Paulo. Agora, v. 23, n. 47, 2013. Disponível } \\
\text { em: <http://basessibi.c3sl.ufpr.br/brapci/v/a/14885>. Acesso em: } 23 \\
\text { Nov. } 2017 \text {. }\end{array}$ & $\begin{array}{l}\text { A informação orgânica é definida como aquela produzida internamente em decorrência da execução das atividades } \\
\text { empresariais. } \\
\text { A informação orgânica é gerada em decorrência da execução das funções organizacionais, pelos próprios membros } \\
\text { da organização, que ao mesmo tempo são produtores e consumidores, encontram-se contidos nos registros físico } \\
\text { das transações de atividades, tarefas ou tomada de decisão. } \\
\text { Outra definição interessante e que se enquadra no nosso entendimento é oferecida por Carvalho e Longo (2002, } \\
\text { p.115):[...] informação orgânica é um conjunto de informações sobre um determinado assunto, materializado em } \\
\text { documentos arquivísticos e foram produzidas no cumprimento das atividades e funções da organização. }\end{array}$ \\
\hline & $\begin{array}{l}\text { TOGNOLI, N. L. B. A informação no contexto arquivístico: uma } \\
\text { discussão a partir dos conceitos de informação-como-coisa e } \\
\text { informação orgânica. Informação Arquivística, v. 1, n. 1, 2012. } \\
\text { Disponivel em: <http://basessibi.c3sl.ufpr.br/brapci/v/a/18240>. } \\
\text { Acesso em: } 24 \text { Nov. } 2017 \text {. }\end{array}$ & $\begin{array}{l}\text { Aqui, a informação orgânica é definida como aquela que é produzida e/ou recebida no âmbito de uma atividade, e } \\
\text { a produção de uma ou mais informações orgânicas darão origem aos arquivos da instituição. Já as informações não } \\
\text { orgânicas são aquelas contidas em documentos bibliográficos, como as publicações e os materiais de referências, } \\
\text { por exemplo. }\end{array}$ \\
\hline & $\begin{array}{l}\text { LOUSADA, M.; VALENTIM, M. L. G. P. Informação orgânica como } \\
\text { insumo estratégico para a tomada de decisão em ambientes }\end{array}$ & $\begin{array}{l}\text { A Informação orgânica é produzida no ambiente interno da organização sendo produto das atividades } \\
\text { desempenhadas no exercício de suas funções. }\end{array}$ \\
\hline
\end{tabular}


competitivos: estudo nas empresas do setor varejista situadas na cidade de Marília/SP. Tendências da Pesquisa Brasileira em Ciência da Informação, v. 5, n. 1, 2012. Disponível em: <http://basessibi.c3sl.ufpr.br/brapci/v/a/13216>. Acesso em: 23 Nov. 2017.

6. OLIVEIRA, M.; BORTOLIN, S. Memória institucional da associação brasileira de educação em ciência da informação (ABECIN); memória institucional de la Asociación Brasileña de Educación em Ciencias de la Información (ABECIN). Informação @ Profissões, v. 1, n. 1/2, 2012 Disponível em: <http://basessibi.c3sl.ufpr.br/brapci/v/a/18157>. Acesso em: 24 Nov. 2017

7. TOGNOLI, N. L. B.; GUIMARÃES, J. A. C. A organização do conhecimento arquivístico: perspectivas de renovação a partir das abordagens científicas canadenses. Perspectivas em Ciência da Informação, v. 16, n. 1, p. 21-44, 2011. Disponível em: <http://basessibi.c3sl.ufpr.br/brapci/v/a/9883>. Acesso em: 24 Nov. 2017.

Após análise da literatura, adotou-se como referência teórica para este trabalho a definição dos pesquisadores Rousseau e Couture (1998, p.64) “[ ".] A informação pode ser orgânica, isto é elaborada, enviada no âmbito da sua missão, ou não orgânica isto é, produzida fora do âmbito desta".

Desse modo, avaliou-se ser fundamental incluir no presente trabalho dois termos: a informação arquivística e informação orgânica que está relacionada ao organismo produtor. Em outras palavras, são as informações geradas dentro do contexto do exercício das funções/objetivos da entidade produtora. Essa característica orgânica significa também que a informação deve guardar entre si as mesmas relações formadas entre as competências e as atividades das organizações, quer sejam públicas, quer sejam privadas.

A Arquivística Integrada - enunciada pela Escola de Québec - que propõe a reintegração da disciplina por meio do ciclo vital dos documentos e uma possível aproximação com a Ciência da Informação, graças à incorporação do termo informação orgânica registrada, como substituição ao termo documento de arquivo

Os termos informação orgânica e informação não-orgânica são frutos da abordagem quebequense. Aqui, a informação orgânica é definida como aquela que é produzida e/ou recebida no âmbito de uma atividade e a produção de uma ou mais informações orgânicas darão origem aos arquivos da instituição. Já as informações nãoorgânicas são aquelas contidas em documentos bibliográficos, como as publicações e os materiais de referências, por exemplo.

8. LOUSADA, M.; VALENTIM, M. L. G. P. Modelos de tomada de decisão e sua relação com a informação orgânica. Perspectivas em Ciência da Informação, v. 16, n. 1, p. 147-164, 2011. Disponível em: $<$ http://basessibi.c3sl.ufpr.br/brapci/v/a/9885>. Acesso em: 1 Dez. 2017.

9. GAMA, F. A.; FERNEDA, E. A mediação da informação nos arquivos permanentes: serviços de referência arquivística no ambiente digital. Informação \& Informação, v. 15, n. 2, p. 147-168, 2010 Disponível em: <http://basessibi.c3sl.ufpr.br/brapci/v/a/9791> Acesso em: 20 Nov. 2017.

Nomeamos a informação produzida internamente a uma determinada organização como informação orgânica, visto que é gerada em decorrência do cumprimento das funções organizacionais, pelos próprios colaboradores da organização que, ao mesmo tempo, são produtores e consumidores.

Um dos enfoques da $\mathrm{Cl}$ é a informação orgânica, ou arquivística, a qual é produzida por um indivíduo ou uma instituição no exercício de suas funções e atividades administrativas. Essa informação encontra-se registrada em documentos de arquivo, que tem um ciclo de vida que pode ser dividido em três fases integradas: corrente intermediária e permanente.

A informação orgânica é produzida por entidades, ou seja, indivíduos e instituições no exercício de funções e atividades por meio do registro em documentos de arquivo. 


\subsection{Informação Arquivística}

No segundo momento da pesquisa foi realizada a busca pelo termo "informação arquivística" (2010 até 2017 na BRAPCI). Foram recuperados 114 registros, porém pelo menos 73 destes foram recuperados, pois são artigos publicados na revista que tem o mesmo nome, Informação Arquivística. Dessa forma, foi reduzida a pesquisa por título + informação orgânica (sem aspas). O resultado foi de 33 publicações, sendo possível identificar, que as revistas que mais publicam nessa temática são: Pesquisa Brasileira em Ciência da Informação e Biblioteconomia, Arquivística.net, Ciência da Informação, Informação Arquivística, a exemplo como apresentado na figura 2 .

Figura 2: Print-Screen página da BRAPCl -resultados para informação arquivística

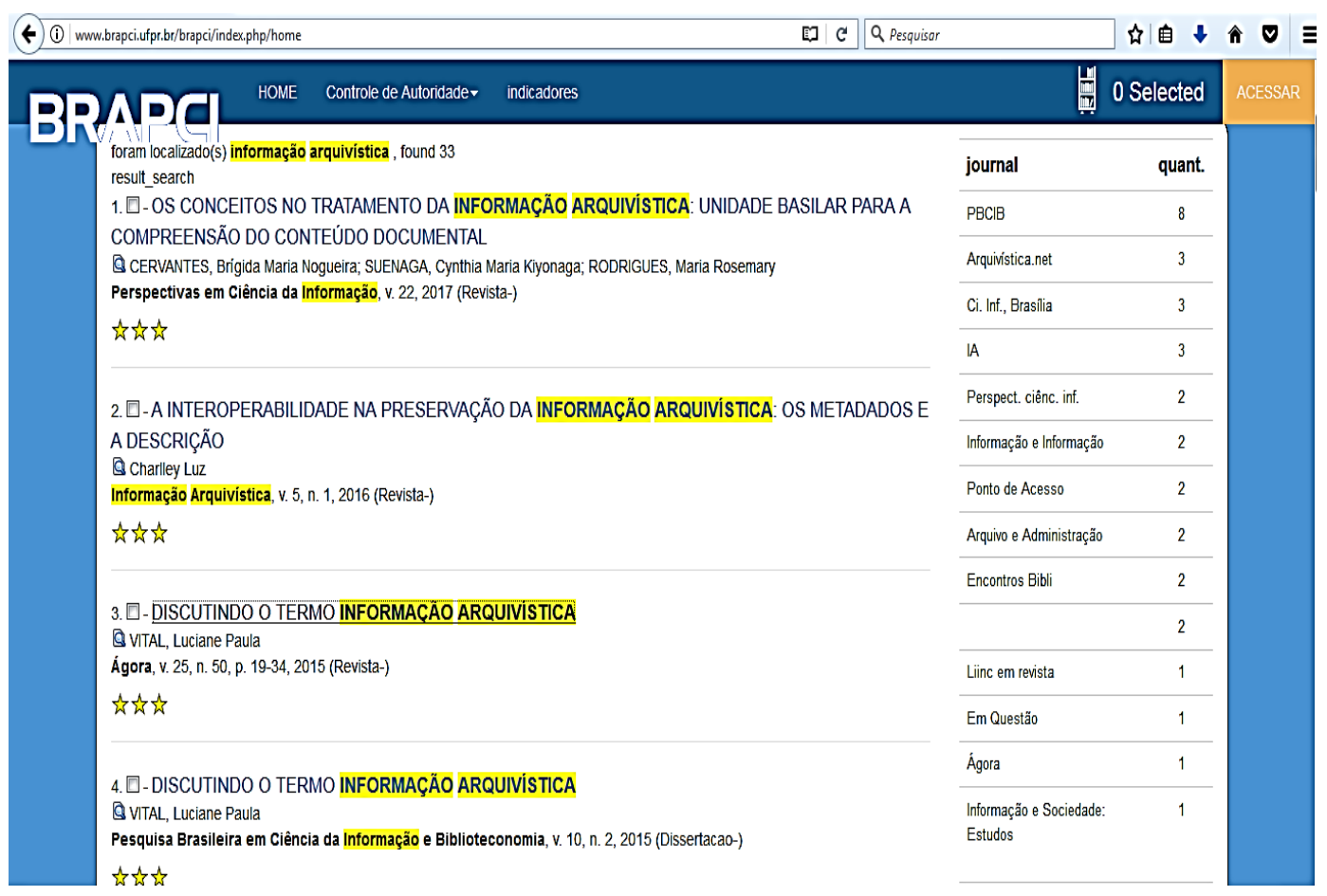

Fonte: Dados da pesquisa, 2017

Mesmo colocando o filtro nos anos de 2010 até 2017, a base recuperou diversos trabalhos de anos antecessores, além de repetir quatro trabalhos. Dessa forma, foram considerados somente os que se enquadram em 2010 até 2017 e não repetidos. Dentre estes foram selecionados os parágrafos que abordavam definições e contextualizações relacionadas à informação arquivística. Como apresentado no quadro 2. 
Quadro 2:Apresentação das definições recuperadas para o termo “informação arquivística”.

1- LUZ, C. A interoperabilidade na preservação da informação arquivística: os metadados e a descrição. Informação Arquivística, v. 5, n. 1, 2016. Disponível em:

<http://www.brapci.ufpr.br/brapci/v/a/23276>. Acesso em: 23 Out. 2017.

O aspecto orgânico é importante, pois é o que caracteriza a informação arquivística, como utilizaremos neste trabalho. Pode-se imaginar que a "organicidade é revelada pelo inter-relacionamento e pelo contexto de existência e de criação." (SOUSA, 2014, p. 7). Parte desta organicidade é evidenciada na forma de Informação Arquivística.

2 - VITAL, L. P. Discutindo o termo informação arquivística. Ágora, v. 25, n. 50, p. 19-34, 2015. Disponível em: <http://www.brapci.ufpr.br/brapci/v/a/17199>. Acesso em: 23 Nov. 2017.

Na Revista Archives (1988 apud LOPES, 2009, p. 119) são apresentadas características da informação arquivística: - a natureza das informações arquivísticas é específica; trata-se de informações registradas em suporte definido, acumuladas por um indivíduo ou por um organismo que é, ao mesmo tempo, produtor e receptor; - a primeira característica da informação arquivística é a sua natureza orgânica, isto é, sua relação umbilical com o produtor; - a segunda característica é a sua originalidade, logo, a sua unicidade; - a terceira característica é a sua capacidade de ser avaliada em termos de idade e de utilização;

3- SENA, J. M. E.; MELLO FILHO, L. L. O. A informação arquivística e a gestão de documentos: uma abordagem estratégica. Informação Arquivística, v. 3, n. 1, 2014. Disponível em: <http://www.brapci.ufpr.br/brapci/v/a/18262>. Acesso em: 23 Nov. 2017

A informação arquivística se concretiza em documentos arquivísticos que mantêm relações orgânicas entre si, pois foram produzidos e acumulados no cumprimento das atividades e funções da organização.

A informação arquivística é produzida dentro do exercício das funções/objetivos a que se propõem as entidades e tem papel fundamental, pois faz parte dos recursos informacionais, que ao lado dos recursos humanos, financeiros e materiais, toda organização utiliza para seu funcionamento. (Moreno, 2006, p. 17).

4- CONCEIÇÃO, A. S. Informação arquivística: o [in]sumo da sociedade contemporânea- a riqueza das organizações. Archeion Online, 2013. Disponível em: <http://www.brapci.ufpr.br/brapci/v/a/18604>. Acesso em: 23 Nov. 2017

5- SFREDDO, J. A.; FLORES, D. Segurança da informação arquivística: o controle de acesso em arquivos públicos estaduais. Perspectivas em Ciência da Informação, v. 17, n. 2, p. 158-178, 2012. Disponível em: <http://portaldeperiodicos.eci.ufmg.br/index.php/pci/article/view/1290/1034>. Acesso em: 24 Nov. 2017.

6 - SILVA, E.. Informação arquivística e Arquivologia no Brasil. Informação Arquivística, 1, out. 2012. Disponível em: <http://www.aaerj.org.br/ojs/index.php/informacaoarquivistica/article/view/5>. Acesso em: 07 Nov. 2017.

Desviando-me de um tom introdutório, é salutar deixar claro que a informação arquivística é aquela que é recebida ou gerada por organizações ou pessoas durante o desenvolvimento de suas respectivas atividades nas organizações.

A informação arquivística pode ser definida de forma que o conteúdo presente nos documentos contextualize ações sistematizadas e organizadas em uma instituição, produzindo, com sua metodologia arquivística, subsídios para a organização documental.

A dimensão de inovação no emprego da expressão informação arquivística ainda não está clara. No entanto, essa utilização é justificada, por alguns dos autores analisados, como mais vantajosa à compreensão das funções arquivísticas, em relação ao conceito de documento de arquivo. $O$ informacional estaria mais adequado à realidade das tecnologias de comunicação e informação, associada à demanda por padronização internacional dos elementos de identificação dos acervos arquivísticos. 


\section{Análise dos resultados}

De acordo com o que foi apresentado, dá-se início a análise de dados inferindo que para os autores estudados há duas motivações principais relativas à incorporação do termo informação na Arquivologia. O primeiro diz respeito à era informacional e tecnológica assistida, o termo documento de arquivo não condiz mais com a realidade virtual e digital. Documentos de arquivo são criados a todo minuto em formato digital e não serão mais impressos ou materializados em suporte papel como foram por muito tempo.

Essa troca de suporte é também considerada uma justificativa para o uso do termo informação. Como traz Silva $(2012$, p. 20)“O informacional estaria mais adequado à realidade das tecnologias de comunicação e informação, associada à demanda por padronização internacional dos elementos de identificação dos acervos arquivísticos". Ainda para Tognoli "ao definir o objeto da Arquivística como a informação orgânica registrada, a abordagem quebequense busca inserir a disciplina na chamada 'era da informação'” (TOGNOLI, 2012, p. 120).

O segundo ponto se dá a partir de uma necessidade de interlocução com a Ciência da Informação, tendo as duas como objeto de estudo a informação, os laços estariam estreitados.

Seguindo a análise dos dados, serão apresentadas as definições dos termos informação orgânica e informação arquivística.

Quanto à informação orgânica, nas publicações identificadas são utilizadas citações de outros autores, como: Couture e Rousseau, quando tratam da origem da informação orgânica, na arquivística integrada como mencionado na terceira sessão. Dos nove artigos analisados, todos possuem dentre as referências os autores Rousseau e Couture (1998). Dessa forma, é possível perceber a influência da arquivística integrada no contexto da Arquivologia brasileira nesses nove que abordam os autores, concordando no geral que a informação orgânica é definida como aquela que é produzida e/ou recebida no âmbito de uma atividade. Nas definições, autores como: Tognoli e Guimarães (2011); Barros (2015); Gama e Ferneda (2010); consideram que o uso do termo informação orgânica possui como objetivo maior a aproximação da Arquivologia coma Ciência da Informação. Nesse sentido o termo informação orgânica estaria substituindo o termo documento de arquivo. Segundo Barros (2015, p. 139) para "dar cabo de todos os processos de tratamento recentes desenvolvidos no âmbito da Arquivística, a macroavaliação, a gestão de documentos em ambientes digitais, a representação em arquivos etc.".

Há de se destacar outros resultados: as autoras Lousada e Valentim (2012), umas das que possuem o maior número de publicações nessa temática, utilizam como referência Rousseau e Couture apresentando a seguinte citação: (1998, p. 64)“[...] A informação pode ser 
orgânica, isto é elaborada, enviada no âmbito da sua missão, ou não orgânica isto é, produzida fora do âmbito desta". Mas na escrita dos autores: "pode ser orgânica, isto é, elaborada, enviada ou recebida no âmbito da sua missão, ou não orgânica, isto é, produzida fora do âmbito desta" (ROUSSEAU; COUTURE, 1998, p. 64).Dessa forma, as autoras discordam quando estes apresentam que a informação orgânica é aquela produzida e recebida no cotidiano de uma organização. De acordo com outro artigo identificado na pesquisa também de Lousada e Valentim trazem o seguinte:

\begin{abstract}
Nomeamos a informação produzida internamente a uma determinada organização como informação orgânica, visto que é gerada em decorrência do cumprimento das funções organizacionais, pelos próprios colaboradores da organização que, ao mesmo tempo, são produtores e consumidores. (2011, p. 156).
\end{abstract}

As autoras afirmam que consideram somente o que é produzido pela organização como informação orgânica, o que foi recebido não seria considerado como informação organicamente acumulada pelas instituições em suas atribuições diárias.

Quanto à informação arquivística, é apresentada a partir de diferentes olhares, mas havendo consenso nas afirmações, como para Luz (2016) em que o aspecto orgânico é uma característica da informação arquivística. Vital (2015) também concorda que a informação arquivística tem as seguintes características: natureza orgânica, originalidade e capacidade de ser avaliada em termos de idade e de utilização. Sena e Mello Filho (2014) consideram que a informação arquivística se concretiza em documentos arquivísticos que mantêm relações orgânicas entre si. Para Sfreddo e Flores (2012) a informação arquivística pode ser definida de forma que o conteúdo presente nos documentos contextualize ações sistematizadas e organizadas em uma instituição. Em geral, esses autores concordam que a informação arquivística teria como característica a organicidade, considerando-os como termos diferentes.

Por outro lado, para Silva (2012)a dimensão de inovação no emprego da expressão informação arquivística ainda não está clara. Porém, essa utilização é justificada, por alguns dos autores analisados, como mais vantajosa à compreensão das funções arquivísticas, em relação ao conceito de documento de arquivo. Considerando que informação arquivística estaria substituindo o conceito de "documento de arquivo".

Ainda Conceição (2013) afirma que a informação arquivística é aquela que é recebida ou gerada por organizações ou pessoas durante o desenvolvimento de suas respectivas atividades nas organizações. Essa definição dada por Conceição remete de acordo com o que foi apresentado nessa pesquisa, com o conceito de informação orgânica.

Sob o viés de Dahlberg (1978) a partir da teoria do conceito onde aborda que as definições são a fixação do conteúdo de um conceito e que o conceito tem por conteúdo um 
conjunto de características ou atributos, serão identificadas agora as características presentes nas definições de informação orgânica e informação arquivística. Para isto, foi selecionado o texto apresentado nos quadros 1e 2 . Após a retirada dos artigos, verbos de ligação e preposições foram criadas duas nuvens de palavras e constantes na figura 4.

Figura 4 - Nuvens de termos para informação orgânica e informação arquivística, respectivamente
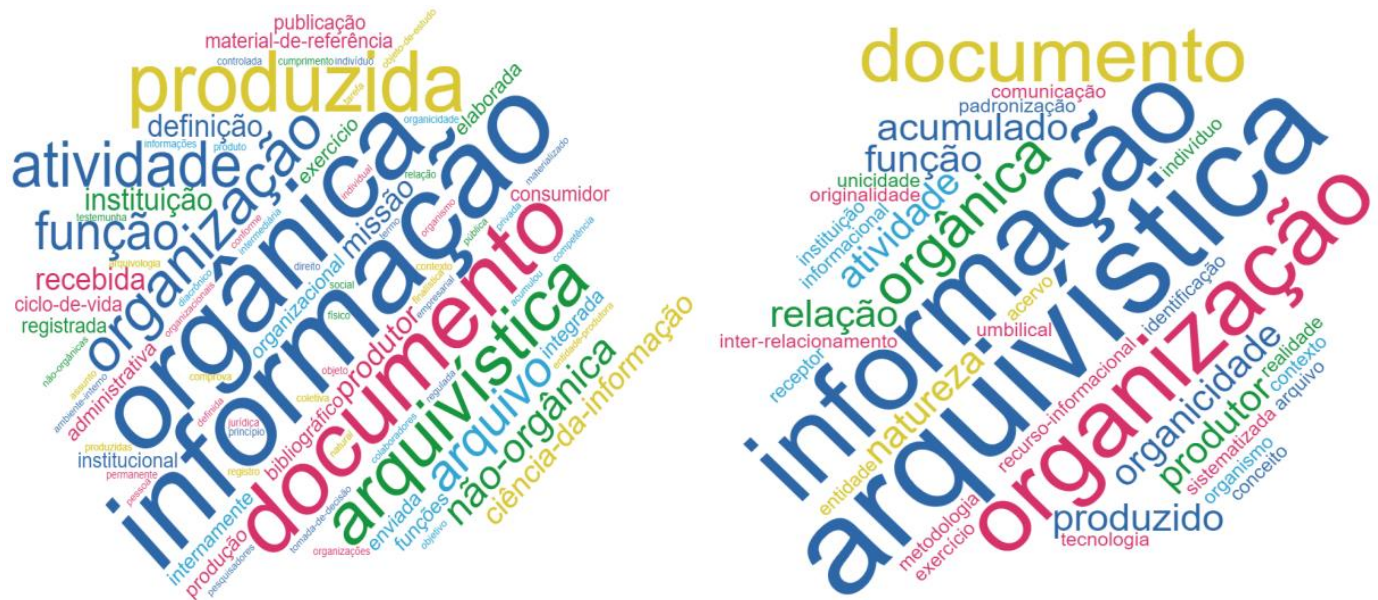

Fonte: Elaboração dos autores via wordclouds.com, 2018.

Os quinze primeiros termos com mais ocorrência para informação orgânica foram: informação, orgânica, documento, produzida, arquivística, organização, atividade, arquivo, função, não-orgânica, ciência da informação, instituição, definição, produtor, recebida.

Já para informação arquivística foram: arquivística, informação, organização, documento, orgânica, organicidade, atividade, acumulado, produzido, produtor, natureza, relação, funções, recurso-informacional, inter-relacionamento, funções arquivísticas.

\section{Considerações finais}

Para iniciar as considerações vale destacar os dois motivos principais da inserção do termo informação no escopo da Arquivologia, o primeiro, quanto a interlocução com a $\mathrm{Cl}$, e o segundo relacionado ao alargamento do termo documento de arquivo diante das tecnologias aplicadas aos arquivos.

De acordo com os objetivos pré-estabelecidos, os autores que mais têm publicado a respeito de informação orgânica e arquivística dentro da seleção da pesquisa, são: Lousada, Lousada e Valentim; Tognoli, Tognoli e Guimarães; respectivamente. Tanto Lousada quanto Tognoli são arquivistas, Valentim e Guimarães são bibliotecários. O que demonstra que a investigação sobre o fenômeno informação vai além da disciplina arquivística. 
Quanto às autoras Lousada e Valentim, trazendo novamente o artigo citado na coleta de dados, intitulado "Información archivística e información orgánica: um análisis conceptual de la literatura brasileña de $2010 "$, consideram que:

La información orgánica es por naturaleza archivística pues es el resultado de las acciones de la organización/ institución. Sin embargo, la información archivística no siempre es orgánica en el sentido de que no se produce necesariamente en una organización específica, es decir, puede haber sido producida en lugares externos a la organización. (LOUSADA; VALENTIM, 2010, p. 407).

Essa visão das autoras Lousada e Valentim é fruto do já citado entendimento de que o que é recebido não é considerado informação orgânica e para tanto a distinção entre os termos informação orgânica e informação arquivística estaria na última abranger também o recebido e a primeira se restringir somente ao que foi produzido pela instituição, o que não é considerado aqui.

É certo que realmente há certa confusão quando se trata da utilização dos dois termos estudados. O que se procurou aqui não foi definir quem está certo ou errado, mas gerar hipóteses para essas definições.

Analisando as nuvens de termos apresentadas, e considerando o que Dahlberg apresenta como conceito e definição, quando das características das definições, foi possível identificara primeira hipótese dessa pesquisa, de que os termos estão sendo utilizados como sinônimos. As palavras identificadas para informação arquivística, menos natureza, relação, inter-relacionamento, palavras ligadas ao caráter orgânico, estão todas as outras, presentes também no ranking de informação orgânica. Lopes (1996, apud CALDERON, 2013) admite que as expressões podem ser tratadas como sinônimos porque a característica de organicidade, nesse caso, é atribuída em razão de a informação pertencer à organização ou à pessoa que a acumulou e não exatamente em ter sido produzida no âmbito interno da organização.

Dessa forma, o uso do termo informação arquivística ou informação orgânica seria indiferente, as duas seriam tratadas igualmente. Como apresentado na coleta de dados por Gama e Ferneda (2010, p. 148) “Um dos enfoques da Cl é a informação orgânica, ou arquivística, a qual é produzida por um indivíduo ou uma instituição no exercício de suas funções e atividades administrativas". Ainda quanto às nuvens de termos é válido ressaltar que ciência da informação apareceu nas definições de informação orgânica. Mas, não nas de informação arquivística, o que justifica o uso do termo informação orgânica para estreitar os laços entre a $\mathrm{Cl}$ e a Arquivologia.

A segunda hipótese estabelecida após a análise é de que a informação arquivística está presente quando se trata do sentido cognitivo da informação, como estruturado conjunto de representações mentais, que podem ser exteriorizadas, podendo ser comunicada gerando o 
fenômeno conhecimento. Segundo os autores Sfreddo e Flores (2012, p. 159): “A informação arquivística pode ser definida de forma que o conteúdo presente nos documentos contextualize ações sistematizadas e organizadas em uma instituição, produzindo, com sua metodologia arquivística, subsídios para a organização documental". Relacionada então ao conteúdo, ao que há de informação no documento e como o documento criará no leitor as representações mentais do assunto.

Já quanto à informação orgânica estaria ligada a essa materialidade da informação arquivística, esse registro em suporte seria a informação orgânica, como o resultado das ações desenvolvidas por uma organização no decorrer de suas atividades. Para Carvalho e Longo (2002, p. 115):informação orgânica é um conjunto de informações sobre um determinado assunto, materializado em documentos arquivísticos e foram produzidas no cumprimento das atividades e funções da organização. Deixando mais próximo da visão de que a informação orgânica substitui o termo documento de arquivo.

A terceira hipótese, ainda seria a partir de uma análise fenomenológica, ou seja, com o propósito de descobrir estruturas essenciais dos atos e as entidades objetivas que correspondem a essa estruturas, caracterizando cada artigo de acordo com a corrente arquivística que segue e a partir disso, se pudesse categorizar as definições de acordo com a visão do autor, se é integrada, pós-moderna. O que não foi possível identificar aqui, e que caberia uma análise aprofundada sobre o tema. Porém, a prima vista é possível detectar que seria uma árdua tarefa, visto que perante a leitura dos artigos, as referências arquivísticas se misturam, não seguindo uma ordem do fenômeno que gerou a ideia.

Conclui-se então esse artigo deixando claro que o assunto não se esgota, há ainda outros questionamentos e muitos estudos a serem desenvolvidos nesse sentido. Segundo Moreno (2007, p. 9) "a noção de informação arquivística ou informação orgânica é recente na literatura da área e ainda precisa de aprofundamento teórico". Tornar consensual ou menos ambígua a definição de informação orgânica e informação arquivística é ponto crucial quando se está considerando-a como objeto/base de estudo de uma ciência.

\section{Referências}

ABBAGNANO, Nicola. Dicionário de Filosofia. São Paulo: Martins Fontes. 2003.

ARAÚJO, C. A. V. Epistemologia da arquivologia: fundamentos e tendências contemporâneas. Ciência da Informação, v. 42, n. 1, p. 50-63, 2013. Disponível em: <http://www.brapci.inf.br/v/a/16753> Acesso em: 21 Nov. 2017. 
ARAÚJO, Carlos Alberto Ávila. Arquivolologia, Biblioteconomia, Museologia e Ciência da Informação: o diálogo possível. Brasília, DF: Briquet de Lemos, 2014. 200 p.

ARAÚJO, Carlos Alberto Ávila. Correntes teóricas da Arquivologia. Encontros Bibli: Revista Eletrônica de Biblioteconomia e Ciência da Informação, Florianópolis, v. 18, n. 37, p. 61-82, ago. 2013. ISSN 1518-2924. Disponível em: <https://periodicos.ufsc.br/index.php/eb/article/view/1518-2924.2013v18n37p61/25338>

Acesso em: 11 nov. 2017.

BARROS, Thiago H. B; MARTINS, Wanessa R. Informação orgânica enquanto um objeto interdisciplinar: as relações entre a Arquivística e a Ciência da Informação no âmbito da representação em arquivos. Ágora, Florianópolis, v.25, n.51, p.132-149, jul./dez., 2015.

BRASIL. Arquivo Nacional. Dicionário brasileiro de terminologia arquivística. Rio de Janeiro, 2005. 232p., Publicações Técnicas, n. 51. Disponível em: <http://www.arquivonacional.gov.br/images/pdf/Dicion_Term_Arquiv.pdf > Acesso em 30 nov. 2017.

BRITO, Jahyr Jesus. A Laicização na reforma da ONU:A Teoria Da Soberania No Século XXI. São Paulo: Max Limonad, 2017.

CALDERON, Wilmara Rodrigues. $\mathbf{O}$ arquivo e a informação Arquivística: da literatura científica à prática pedagógica no Brasil. São Paulo. Cultura Acadêmica. 2013.

CONCEIÇÃO, A. S. Informação arquivística: o [in]sumo da sociedade contemporânea- a riqueza das organizações. Archeion Online, 2013. Disponível em: <http://www.brapci.inf.br/index.php/article/view/0000018604/4c5c42c634e00085ef3bb9261 1b50f24> Acesso em: 10 Ago. 2018

COOK, Terry. Arquivos pessoais e arquivos institucionais: para um entendimento arquivístico comum da formação da memória em um mundo pós-moderno. Estudos Históricos, Rio de Janeiro, v. 11, n. 21, p. 129-149, 1998.

DAHLBERG, I. Knowledge organization: its scope and possibilities. Knowledge Organization, v. 20, n. 4, 1993, p. 211- 222.

DAHLBERG, I. Teoria do conceito. Ciência da Informação, Brasília, v.7, n.2, p.101-107, 1978.

GAMA, F. A.; FERNEDA, E. A mediação da informação nos arquivos permanentes: serviços de referência arquivística no ambiente digital. Informação \& Informação, v. 15, n. 2, p. 147-168, 2010.

Disponível em: <http://www.uel.br/revistas/uel/index.php/informacao/article/view/7352> Acesso em: 10 Ago. 2018.

HJORLAND, D. Semantics and knowledge organization. Annual Review of information Science and Technology, v. 41, p. 367-405, 2007. 
LOPES, Luís Carlos. Os arquivos, a gestão da informação e a reforma do estado. Arquivo \& História, Rio de Janeiro, n. 4, p. 37-49, out. 1998.

LOUSADA, M. A produção documental orgânica em pequenas empresas do setor varejista de Marília/São Paulo. Ágora, v. 23, n. 47, 2013. Disponível em: <https://agora.emnuvens.com.br/ra/article/view/441> Acesso em: 10 Ago. 2018.

LOUSADA, M.; VALENTIM, M. L. G. P. Informação orgânica como insumo estratégico para a tomada de decisão em ambientes competitivos: estudo nas empresas do setor varejista situadas na cidade de Marília/SP. Tendências da Pesquisa Brasileira em Ciência da Informação, v. 5, n. 1, $2012 . \quad$ Disponível em: <http://www.brapci.inf.br/index.php/article/view/0000013216/58c565841ebff7b148cf778e4e ee76> Acesso em: 10 Ago. 2018.

LUZ, C. A interoperabilidade na preservação da informação arquivística: os metadados e a descrição. Informação Arquivística, v. 5, n. 1, 2016. Disponível em: <http://www.brapci.inf.br/index.php/article/view/0000023276/40414a4186c1d86ad3b0125ae fe8f5f1> Acesso em: 10 Ago. 2018.

MELO, M. A. F.; BRÄSCHER, M. Termo, conceito e relações conceituais: um estudo das propostas de Dahlberg e Hjorland. Ciência da Informação, Brasília, DF, v. 41 n. 1, p. 67-80, jan./abr., 2014. Disponível em: <http://revista.ibict.br/ciinf/article/view/1419> Acesso em 30 nov. 2017.

MESSIAS, Lucilene Cordeiro da Silva. Informação: um estudo exploratório do conceito em periódicos científicos brasileiros da área de Ciência da Informação. 2005. 184 f. Dissertação (Mestrado) - Curso de Pós-graduação em Ciência da Informação, Faculdade de Filosofia e Ciências, Universidade Estadual Paulista - Unesp, Marília, 2005. Disponível em: <https://www.marilia.unesp.br/Home/Pos-

Graduacao/Cienciadalnformacao/Dissertacoes/messias_Ics_me_mar.pdf> Acesso em: 22 jun. 2018.

MORENO, N. A. A informação arquivística e o processo de tomada de decisão. Informação \& Sociedade, João Pessoa, v.17, n.1, p.9-19, jan./abr. 2007. Disponível em: <http://www.brapci.inf.br/index.php/article/view/0000007629/c66322953e4ed32d1779f48aa fc129b2> Acesso em: 10 Ago. 2018.

OLIVEIRA, M.; BORTOLIN, S. Memória institucional da associação brasileira de educação em ciência da informação (ABECIN); memória institucional de la asociación brasileña de educación em ciencias de la información (ABECIN).Informação @ Profissões, v. 1, n. 1/2, 2012. Disponível em: <http://www.uel.br/revistas/uel/index.php/infoprof/article/view/14594> Acesso em: 10 Ago. 2018.

ROCKEMBACH, M. Difusão em arquivos: uma função arquivística, informacional e comunicacional .Informação Arquivística, v. 4, n. 1, 2015. Disponível em: <http://www.brapci.inf.br/index.php/article/view/0000018223/2551f7f6be23d0dace3b8813d 0b2909e/> Acesso em: 10 Ago. 2018. 
SCHMIDT, Clarissa Moreira dos Santos. Arquivologia e a construção do seu objeto científico: concepções, trajetórias, contextualizações. Tese (Doutorado em Ciência da Informação) Universidade de São Paulo, 2012.

SENA, J. M. E.; MELLO FILHO, L. L. O. A informação arquivística e a gestão de documentos: uma abordagem estratégica. Informação Arquivística, v. 3, n. 1, 2014. Disponível em: <http://www.brapci.inf.br/index.php/article/view/0000018262/5b3cadb4e8227f005a78dbe78 d33af7c> Acesso em: 10 Ago. 2018.

SFREDDO, J. A.; FLORES, D. Segurança da informação arquivística: o controle de acesso em arquivos públicos estaduais. Perspectivas em Ciência da Informação, v. 17, n. 2, p. 158-178, $2012 . \quad$ Disponível em: <http://www.brapci.inf.br/index.php/article/view/0000012726/87225b35937de55f0e159bc66 c1421db/> Acesso em: 10 Ago. 2018.

SILVA, Armando Malheiro et al. Arquivística: teoria e prática de uma Ciência da Informação. 3. ed. Porto: Afrontamento, 2009. 254 p.

SILVA, E. Informação arquivística e Arquivologia no Brasil. Informação Arquivística, v. 1, out. 2012. Disponível

em: <http://www.aaerj.org.br/ojs/index.php/informacaoarquivistica/article/view/5> Acesso em: 07 Nov. 2017.

SILVA, Elieser P. da. O conceito de informação arquivística. In: ENCONTRO NACIONAL DE PESQUISA EM CIÊNCIA DA INFORMAÇÃO - ENANCIB. GT 1 - Estudos históricos e epistemológicos da Ciência da Informação. Rio de Janeiro, Out. 2010. Disponível em: <http://enancib.ibict.br/index.php/enancib/xienancib/paper/viewFile/3384/251> Acesso em: 10 Ago. 2018.

TOGNOLI, Natália L. B. A contribuição epistemológica canadense para a construção da arquivística contemporânea. Dissertação (Mestrado em Ciência da Informação). Marília, SP, 2010. $120 \mathrm{f}$

TOGNOLI, Natália L. B. A informação no contexto arquivístico: uma discussão a partir dos conceitos de informação-como-coisa e informação orgânica. Informação Arquivística, Rio de Janeiro, v. 1, n. 1, p. 113-122, jul./dez. 2012.

TOGNOLI, Natália L. B.; GUIMARÃES, José A. C. A organização do conhecimento arquivístico: perspectivas de renovação a partir das abordagens científicas canadenses. Perspectivas em Ciência da Informação, Belo Horizonte, v. 16, n. 1, p. 21-44, 2011. Disponível em: <http://portaldeperiodicos.eci.ufmg.br/index.php/pci/article/view/1084/832> Acesso em: 4 nov. 2017.

VITAL, Luciane P. Discutindo o termo informação arquivística. Ágora, v. 25, n. 50, p. 19-34, 2015. Disponível em: <https://agora.emnuvens.com.br/ra/article/view/525> Acesso em: 10 Ago. 2018 
VALENTIN, Marta Lígia Pomim; LOUSADA, Mariana. Información archivística e información orgánica: un análisis conceptual de la literatura brasileña. In: El Profesional de la Informacion, v.
19 ,
$\mathrm{n}$.
4 ,
2010.
em:

<http://www.elprofesionaldelainformacion.com/contenidos/2010/julio/10.pdf> Acesso em 30 nov. 2017. 